\title{
Profiling Formative Assessment Culture in EFL Teacher Education Programs in the Middle East
}

\author{
Khaled M. El ebyary \\ Curricula and Methods of Instruction Department, Faculty of Education, Damanhour University, Egypt
}

\begin{abstract}
Although there is general agreement that there is a difference between assessment of learning (summative assessment), and assessment for learning (formative assessment), and that both forms of assessment have valuable roles to play, comparatively little attention is given to the latter in foreign language teacher education programs (FLTEPs) in the Middle East. The inclusion of formative assessment in foreign language teacher education curricula is meant to improve student teachers' learning and that is why it generally counts towards the final grades. However, little formative classroom assessment, as compared to summative, is currently provided and as a result, student teachers are unable to benefit from the positive effect this would have on their learning. There is in practice a gulf between the decision-takers' requirements that formative classroom assessment should be used and instructors' distrust in this form of assessment. This research paper assumes that this view is unconsciously inherent in FLTEPs, which is the major channel for training and recruiting teachers of foreign languages at pre-university levels in many Arab states. Therefore, the aim of this study is to provide a snapshot of the implicit/explicit formative classroom assessment culture in FLTEPs in the Middle East.
\end{abstract}

Index Terms - formative assessment, summative assessment, assessment culture

\section{INTRODUCTION}

"What is the benefits of doing X or Y?" is the simplest of questions often asked by those involved in a task, be it as big as Barak Obama desperately planning to imitate George Bush in invading some countries or as small as Joe Bloggs having to deliver a pizza hot to someone who ordered it for dinner. Though discrepant in depth, in/formality and level of complexity, of course, almost very similar assessment processes are undertaken by Mr Obama and Mr Bloggs because both need ongoing assurance that the moves they are making are the right ones otherwise new decisions need to be taken. In order to achieve their desired target(s), each should be willing and committed to carry out procedural formative assessments that would positively, or negatively, influence their final status. Formative classroom assessment (FCA hereafter) is no different. It has always been involved one way or another in the educational landscape although its roles and purposes have been viewed differently according to how the pendulum of interest has swung throughout educational history.

\section{LITERATURE REVIEW: SHIFTING SANDS IN ASSESSMENT}

Until recently, formative assessment has been overshadowed by summative assessment practices in more ways than one. In fact, summative assessment research dominated and comparatively very little attention was given to formative assessment per se to the extent that formative assessment practices appeared unreliable and lacking connection to school assessment approaches (Knight and Yorke, 2003; Torrance and Pryor, 1998; Crooks, 1988). Indeed formative assessment has been overlooked by summative assessment advocates over the last four decades (Jones, 2005; Crooks, 1988) and a sort of conflation between these two assessment strategies is often found in the literature, which has obviously been a prime cause of definitional fuzziness (Yorke, 2003) in the constant attempts to describe formative assessment. In this respect, the term 'formative evaluation' was originally used by Scriven in 1967 in the Methodology of Evaluation, but it was Benjamin Bloom who first used it in his Handbook on the Formative and Summative Evaluation of Student Learning in 1971 with its current meaning (Black and Wiliam, 2003; Wiliam and Black, 1996). Yet, there is still some uncertainty and lack of clarity in relation to the terminology used with formative assessment. Some of the terminology used by researchers includes classroom evaluation (Crooks, 1988; Bloom et al., 1971; Scriven, 1967), teacher assessment (Teasdale and Leung, 2000), classroom assessment (Stiggins, 2002a; McMillan, 2001) classroom-based-assessment (Gipps, 1999), teacher-made assessment (Wildemuth, 1984), in-course assessment (Greer, 2001), learning-oriented assessment (Keppell et al., 2006; Carless et al., 2006), teacher-developed assessment (Stiggins and Bridgeford, 1985), assessment to assist learning (Ash and Levitt, 2003), low-stakes assessment (Wise and DeMars, 2005) or just feedback (Dietel et al., 1991). However, the most recently-coined term is assessment for learning (James and Pedder, 2006; Wiliam et al., 2004).

It was in the last decade or so that FCA has come to the fore. It has even been claimed that this sort of assessment has developed into a prominent research area in its own right. The change in assessment vision has been ascertained by many research experts in different forums (e.g. Black and Wiliam, 1998a; 1998b; Gipps 1999 and others). In fact, 
considerable arguments have been concerned with finding answers to questions such as "Is there a distinctive area where a line can be drawn between assessment and learning?" and "Do they overlap in a rather blurred area where assessment can be dealt with as a learning experience that would engage students into a sort of reasoning?". The advance in our understanding of the learning process and how it takes place has been a major impetus to re-examine and reform education systems and this entailed a shift in the way(s) assessment is perceived. This reconceptualization, as labelled by Anderson (1998) and McMillan (2001), has added to our insights of assessment in general and FCA in particular. The change in assessment purposes has led to the realization of the limitedness of a single assessment technique to serve all purposes. Reliance on objective testing and standardization procedures can be helpful in certification and accountability, but the beneficial element every single student might gain can be maximized through using other forms of assessment, i.e. formative classroom assessment. Although the issue of formative assessment has been reviewed by Natriello (1987) and Crooks (1988), Black and Wiliam's (1998a; 1998b) review is more widely recognized in assessment forums where it has been considered, especially in the UK, the spark for the current inevitable interest in assessment in relation to learning, i.e. assessment for learning (Sadler, 1998).

In their description of the Black Box, Black and Wiliam (1998b) revealed how the pressures on the teaching/learning process is externally managed by some educational bodies with the prime aim of raising standards with the least attention given to what goes on inside the black box. They state "But what is happening inside? How can anyone be sure that a particular set of new inputs will produce better outputs if we don't at least study what happens inside?". In fact, Black and Wiliam (1998a; 1998b) urged the move towards a re-conceptualisation of the trichotomous interrelationship among assessment, teaching and learning. Here, these two authors state:

'one of the outstanding features of studies of assessment in recent years has been the shift in the focus of attention, towards greater interest in the interactions between assessment and classroom learning and away from concentration on the properties of restricted forms of test which are only weakly linked to the learning experiences of students' ( $p .7)$

The move has been widely acknowledged by many researchers (e.g.Irons, 2008; Black et al., 2003; Briggs et al., 2003; Fautley and Savage, 2002; Stiggins, 2002; Shepard, 2000; Boud, 1995). Likewise, many educational bodies have adapted this interrelationship as a cornerstone of their work. Some of these are Qualification and Curriculum Authority (QCA), Department for Children, Schools and Families (DCSF), Department for Education and Skills (DfES), Assessment is for learning (AifL), Centre for Excellence in Teaching \& Learning in Assessment for Learning (CETL AfL) and others. Therefore, Black and Wiliam (1998a) describe formative assessment as 'encompassing all those activities undertaken by teachers, and/or by their students, which provide information to be used as feedback to modify the teaching and learning activities in which they are engaged' (pp.7-8). Similar accounts are also given by Sadler (1998), Dietel et al. (1991), James and Pedder (2006) and Irons (2008).

However, the conflict between the social role of assessment (i.e. the assessment culture) and the educational one often imposes an impediment that might prevent the beneficial impact of formative assessment. Yet, the very nature of this conflict varies from one educational system to another and from one context to the other. This study therefore examines the explicit/implicit formative classroom assessment culture in foreign language teacher education programs in some Middle Eastern countries, i.e. Egypt, Saudi Arabia and Libya.

\section{The Study BaCKGRound AND Methodology}

Foreign language teacher education programs in the Middle East are generally undertaken by Faculties of Education, Arts and sometimes Teacher Education Higher Institutes in certain countries in which student teachers generally enrol on four-year pre-service programs after obtaining their secondary school certificate. The mission of these institutions is mainly to provide pre-service teacher training that would qualify foreign language teachers at a Bachelor level to work as language teachers at the pre-university stages. However, schooling in most Middle Eastern countries can be characterised as an examination oriented system (Hargreaves, 1997) and so are FLTEPs in these countries. Consequently, almost all sorts of classroom practice align with the summative assessment plethora inherited in the education context. In contrast, the challenge of providing realistic formative assessment that would have beneficial impact on student teachers' learning is often questionable in such contexts. The challenge, this researcher suggests, is presumably based on an assessment culture created by a number of forces (e.g. large student numbers) and hence imposed on instructors and student teachers in these contexts. According to this working assessment culture, the sole purpose of FCA is to provide assessment tasks that would simulate the summative ones, i.e. summative use of formative assessment. As a result, a feel of distrust in formative assessment that would imply any sort of dissimilarities with summative ones is generally often the case. This study therefore aimed to provide a snapshot of the implicit/explicit formative classroom assessment culture in foreign language teacher education programs in Egypt, Saudi Arabia and Libya as typical Middle Eastern countries. Other Arab countries in the Gulf area (e.g. Qatar, Bahrain, UAE) were not considered here for a number of reasons the most important of which is that such countries depend on native speakers in EFL teaching in both state schools as well as international accredited schools.

The present study focused on FCA practice in writing classes in which the importance of this sort of assessment has continuously been emphasized in the literature (e.g. Hattie and Timperley, 2007). The study questions, as so will the results, address three major themes. These are a) instructors' views about the purpose/role of FCA for themselves, as well as for students, b) instructors' attitudes towards FCA as well as their perception of the attitudes of other parties that 
might be interested (including students) and c) evaluation with current FCA practice and whether or not there is a need for change. The study questions were therefore tied closely to such themes. These questions were:

1. How far do instructors in the target context have common/different perception of formative assessment purposes?

2. What are instructors' attitudes, as opposed to their perception of their students' attitudes, towards FCA?

3. How do instructors evaluate current practices and how far do they share common views about the need for change?

A. The Study Sample

TABLE 1.

THE STUDY SAMPLE

\begin{tabular}{|l|l|l|}
\hline Country & Questionnaire Participants & Interviewees \\
\hline Egypt & 21 & 3 \\
\hline Saudi & 19 & 3 \\
\hline Libya & 14 & 3 \\
\hline Total & 54 & 9 \\
\hline
\end{tabular}

The sample comprised a total of 63 instructors from different universities within the three countries involved (see table 1). Fifty-four participants responded to a questionnaire. The rest of the participants were interviewed through a semi-structured interview. The sample comprised lecturers, assistant lecturers and demonstrators. These represented 19 universities in all three countries. Egyptian participants came from 9 universities, Saudi came from 6 universities and Libyans came from 4 universities.

\section{B. The Study Instruments and Data}

The study was mainly based on two instruments: a questionnaire and semi-structured interviews. The questionnaire was administered online and was live for 2 months. The questionnaire aimed to elicit data about the three themes mentioned earlier in this study. Participants were reached through networking sampling in which "participants who possess certain characteristics are selected and asked to refer others with similar characteristic" (Lodico et al. 2006). Having established communication with some participants through their contact details as published on the universities web pages, these provided contact details of other participants. A total of 137 invitations were sent off and a total of 63 responses were completed while 56 dropped out after starting and 18 did not respond at all. However, the completion rate was somewhat similar in all three countries (see table 2). Although the overall completion rates of the questionnaire were not very high as compared to the number of the online invitations sent off (see table 2), the respondents came from various universities in all three countries and this would urge the researcher to suggest that the study sample was representative.

TABLE 2.

INSTRUCTORS QUESTIONNAIRE COMPLETION RATE

\begin{tabular}{|l|l|l|l|c|}
\hline & Viewers & Responses & Drop Outs & Completion Rate \\
\hline Egyptians & 53 & 21 & 20 & $51.22 \%$ \\
Saudis & 49 & 19 & 15 & $55.88 \%$ \\
Libyans & 35 & 14 & 21 & $50 \%$ \\
\hline
\end{tabular}

On the other hand, semi-structured interviews were also used with a total of 9 participants distributed evenly with regard to the countries involved. The interviews were conducted online via Skype. The aims of the interviews were to explore the implicit issues brought about in the questionnaire and to find out the extent to which participants might share common perceptions of the need for change. It is noteworthy to mentions that the data obtained from the questionnaire was validated during the interviews.

\section{The STUdy MAIN FINDINGS}

The findings obtained in this study addressed the three main themes described earlier. These themes were the basis on which the assessment culture in the study context was profiled. These were a) instructors' views about the purpose/role of FCA for themselves as well as for students, b) instructors' attitudes towards FCA as well as their perception of the attitudes of other parties that might be interested (including students) and c) evaluation of current FCA practice and whether or not there is a need for change. In the remaining part of this section, findings on such themes are introduced correspondingly.

\section{A. Instructors' Views about FCA}

Investigating instructors' views targeted participants' understanding of the purposes and roles of FCA for instructors themselves, as well as for students. As for instructors' views of the purposes of FCA, a three-point scale was used to elicit their dis/agreement on the following purposes:

- identifying what knowledge and skills have been learnt,

- providing evidence for student current writing performance,

- providing evidence of student long term progress, 
- providing information about what students can do rather what they can not do, and

- monitoring teaching performance.

TABLE 3.

PARTICIPANTS' VIEWS ABOUT THE ROLES OF FCA FOR INSTRUCTORS

\begin{tabular}{|l|l|l|l|l|}
\hline Item & Country & Agree & Neutral & Disagree \\
Identify what & Egypt & $94 \%$ & $0 \%$ & $6 \%$ \\
knowledge and & Saudi & $95 \%$ & $0 \%$ & $5 \%$ \\
skills have been & Libya & $92 \%$ & $8 \%$ & $0 \%$ \\
learnt & Egypt & $97 \%$ & $0 \%$ & $3 \%$ \\
$\begin{array}{l}\text { Provide evidence } \\
\text { for student current }\end{array}$ & Saudi & $80 \%$ & $\mathbf{1 5} \%$ & $5 \%$ \\
$\begin{array}{l}\text { writing } \\
\text { performance }\end{array}$ & Libya & $89 \%$ & $11 \%$ & $0 \%$ \\
$\begin{array}{l}\text { Provide evidence } \\
\text { of student long }\end{array}$ & Egypt & $81 \%$ & $6 \%$ & $13 \%$ \\
term progress & Saudi & $85 \%$ & $5 \%$ & $10 \%$ \\
& Libya & $78 \%$ & $7 \%$ & $14 \%$ \\
$\begin{array}{l}\text { Provide } \\
\text { information about }\end{array}$ & Egypt & $68 \%$ & $16 \%$ & $16 \%$ \\
what students can & Saudi & $55 \%$ & $30 \%$ & $15 \%$ \\
do rather what & Libya & $67 \%$ & $22 \%$ & $11 \%$ \\
they can not do & & & & \\
Monitor Teaching & Egypt & $4 \%$ & $26 \%$ & $70 \%$ \\
Performance & Saudi & $5 \%$ & $40 \%$ & $55 \%$ \\
& Libya & $11 \%$ & $11 \%$ & $87 \%$ \\
& & & &
\end{tabular}

TABLE 4.

PARTICIPANTS' VIEWS ABOUT THE ROLES OF FCA FOR STUDENTS

\begin{tabular}{|l|l|l|l|l|}
\hline Item & Country & Agree & Neutral & Disagree \\
\hline \multirow{3}{*}{$\begin{array}{l}\text { Give students } \\
\text { feedback }\end{array}$} & Egypt & $94 \%$ & $3 \%$ & $3 \%$ \\
\cline { 2 - 5 } & Saudi & $89 \%$ & $6 \%$ & $5 \%$ \\
\cline { 2 - 5 } & Libya & $100 \%$ & $0 \%$ & $0 \%$ \\
\hline \multirow{3}{*}{$\begin{array}{l}\text { Motivate students } \\
\text { Help students }\end{array}$} & Egypt & $90 \%$ & $6 \%$ & $3 \%$ \\
\cline { 2 - 5 } $\begin{array}{l}\text { Saudi } \\
\text { writing QUALITY }\end{array}$ & Libya & $65 \%$ & $25 \%$ & $10 \%$ \\
\cline { 2 - 5 } & Egypt & $97 \%$ & $22 \%$ & $0 \%$ \\
\cline { 2 - 5 } $\begin{array}{l}\text { Help students } \\
\text { produce better } \\
\text { writing QUANTITY }\end{array}$ & Saudi & $75 \%$ & $0 \%$ & $3 \%$ \\
\cline { 2 - 5 } & Libya & $89 \%$ & $15 \%$ & $10 \%$ \\
\cline { 2 - 5 } $\begin{array}{l}\text { Provide evidence of } \\
\text { long-term } \\
\text { performance }\end{array}$ & Saudi & $55 \%$ & $19 \%$ & $3 \%$ \\
\cline { 2 - 5 } & Egyya & $67 \%$ & $15 \%$ & $30 \%$ \\
\cline { 2 - 5 } & Saudi & $53 \%$ & $21 \%$ & $2 \%$ \\
\cline { 2 - 5 } & Libya & $65 \%$ & $23 \%$ & $12 \%$ \\
\hline
\end{tabular}

Participants showed their strong agreement to three main issues in terms of FCA roles for instructors: identifying what knowledge and skills have been learnt, providing evidence for student current writing performance and providing evidence of student long term progress. Less agreement was revealed with regard to providing information about what students can do rather what they cannot do (see table 3 ). However, a considerable number of participants revealed that formative assessment is not viewed as a valid tool to monitor teaching performance. Further elaboration with regard to these issues was brought to the interviews. An overall look at the participants' responses during the interviews, the researcher perceived a feel of summative use of formative assessment among interviewees. The strong agreement participant reflected with regard to identifying what has been learnt, providing evidence for performance and long-term progress and even what students can do rather what they cannot do was mainly because such aspects, according to interviewees, are signs of good achievement in future summative assessments. On the other hand, participants viewpoints indicating that formative assessment is not a valid tool to monitor teaching performance is simply because their contexts are highly summative examination led and the consequences of this type of assessment are often more influential on students' careers. Hence, policies are orientated more towards summative assessment in which instructors and students exert efforts to achieve better marks. According to one participant, 'students would never engage with a formative assessment task in the same way they would with a summative assessment'. Moreover, many viewpoints assumed that students are even distrustful in any type of assessment that might have marginal influence, or even no influence at all, on their marks. Consequently, instructors' lack of enthusiasm enhances distrust in this sort of assessment. Therefore, the majority of instructors see no point in using FCA for monitoring teaching performance.

On the other hand, this paper examined instructors' perception of the role of FCA for students. Almost all participants in the three countries agreed that FCA should provide feedback to students. Although 90\% of Egyptian participants believed that FCA should be a source of motivation, a considerable number of Saudi and Libyan participants ( $25 \%$ and $22 \%$ correspondingly) were neutral about this issue. Furthermore, the majority of participants 
agreed that FCA should improve students' writing quality rather than writing quantity. This was reflected in their responses to the items in table 4. The interviews revealed that such neutrality was because in reality FCA practice is not as frequent as it should be in these contexts, and therefore the impact on students' motivation is minimum. Furth

A considerable number of participants in Egypt, Saudi and Libya expressed their agreement that FCA should provide evidence of student long-term progress $(81 \%, 85 \%$ \& $78 \%$ correspondingly). In this respect, minor responses expressed neutrality and even disagreement. Reasons for such responses were sought in the interviews with instructors. While some views disagreed to attempts of any performance-profiling role of FCA, an examination oriented context, to these participants, would urge students to adhere to certain learning strategies in which they tend to exert efforts in the weeks preceding the final exams memorizing a subject matter.

\section{B. Attitudes}

Other important findings were explored on the dimension of attitudes. In this respect, this paper examined instructors' attitudes towards FCA as opposed to instructors' perception of their students' attitudes towards the same sort of practice. In the same way, the current paper examined instructors' perception of the attitudes of other stakeholders: school administrations and the community in the target contexts at large.

While instructors marked their own positive attitudes towards FCA in Egypt (62\%), Saudi (60\%) and Libya (89\%), $26 \%$ of Egyptian participants, $25 \%$ of Saudis and $11 \%$ of Libyans still revealed neutral attitudes (see figure 1). In comparison, instructors were asked to rate their perception of their students' attitudes towards this sort of practice. In this respect, considerable perception of negative students' attitudes was expressed by instructors (48\% in Egypt, 45\% in Saudi and $2 \%$ in Libya) as opposed to a balanced perception of positive and neutral students' attitudes in all three countries (see figure 2). In terms of instructors' perception of the attitudes of other parties of interest, general neutral attitudes however, were noticed with regard to school administrations in all three contexts (61\% in Egypt, 60\% in Saudi and $41 \%$ in Libya). Although lower ratings were given to the positive attitudes of school administrations, there was a clear perception of low negative attitudes (see figure 3). Instructors' perception of the attitudes of the community at large was not much different to their perception of school administration in terms of neutrality. A general neutral attitudes towards formative assessment by the community was perceived by instructors as opposed to lower negative attitudes and lowest positive ones (see figure 4)

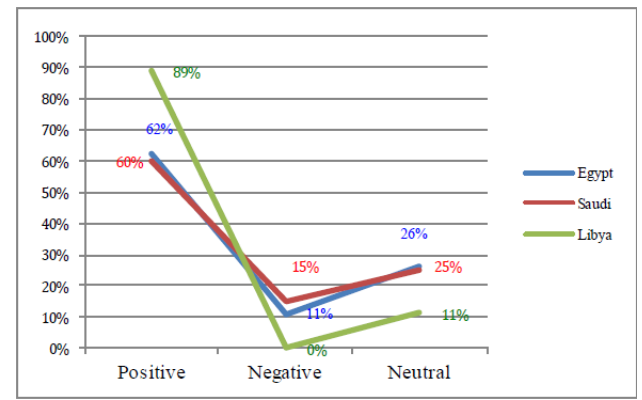

Fig 1. Instructors' attitudes towards FCA

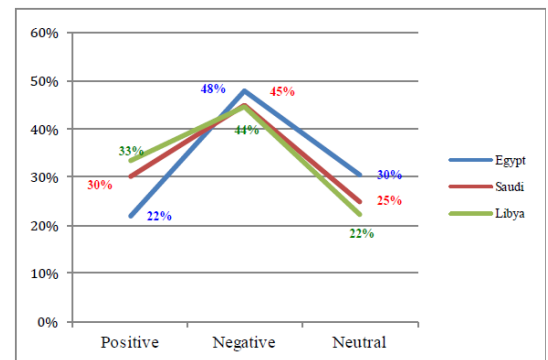

Fig. 2. Instructors' perception of students' attitudes towards FCA

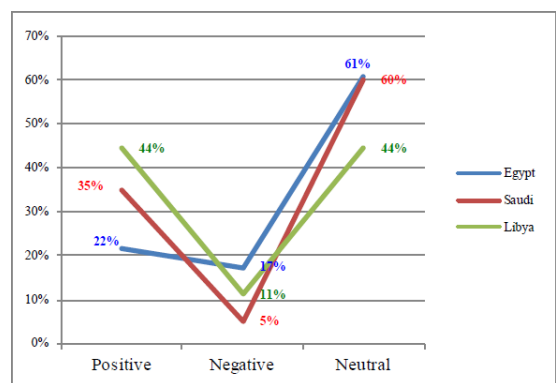

Fig. 3. Instructors' perception of school admin towards FCA 


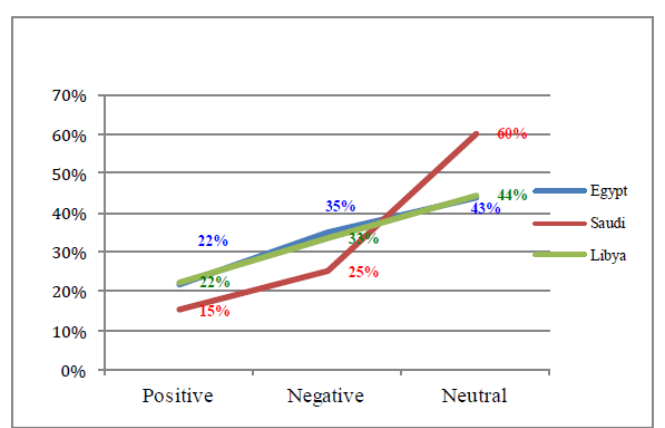

Fig. 4. Instructors' perception of attitudes of the community towards FCA

However, in the interview an important concern voiced by instructors was their constant reference to the wellperceived negative student teachers' attitudes towards FCA practices. Many of them identified the explicit negative attitudes of his/her students towards FCA and the reasons behind that were not very clear to the researcher though mention of the educational system as a summative examination led context was often made. In addition, although many of the instructors expressed their awareness of the potentialities that such an assessment method might bring to students' learning, they revealed their dissatisfaction with the general unvoiced distrust in formative assessment. Moreover, participants indicated the urgent need to device strategies that would improve the perceived negative attitudes.

\section{Evaluation of FCA Practice}

The attempt to evaluate FCA practice in the target contexts focused on participants' own accounts of these practices. This was carried out in a way that would compare to their understanding of FCA purposes for both instructors and students. Table 5 below illustrates such comparisons.

Although participants showed their strong agreement that one purpose of FCA is to be informative for instructors and for student teachers in relation to a number of aspects (see tables $3 \& 4$ above), one emergent result from the instructors' questionnaire was that current FCA is uninformative for instructors. On a five-point scale all participants in three countries rated FCA as below average in terms of reporting what has been learned. Similarly, reflecting students' learning was rated below average in Egypt and Saudi and average in Libya. On the other hand, analysis also revealed that respondents deemed FCA as being either below average or extremely poor in terms of informing student teachers about their own learning, providing feedback and reporting long term progress on such learning (see table 5). Such assessment sort was even rated as below average in Egypt and average in Saud and Libya in motivating to student teachers.

Furthermore, the data revealed that instructors' responses with regard to the extent to which FCA is fulfilling to student teachers' learning objectives align with their responses that indicated their awareness of FCA being fulfilling to course teaching objectives. In this respect, 34\% of Egyptian instructors, $40 \%$ of Saudi and 55\% of Libyan, rated FCA as below average in terms of helping to fulfil the objectives of a course. On the other side, $56 \%$ of Egyptians, $60 \%$ of Saudi and $88 \%$ of Libyan classified current FAC practices roles in helping students fulfil their learning objectives as either below average or extremely poor.

However, further discussion of these issues was a major impetus for exploration during the interviews. It was revealed that instructors' awareness of student teachers' distrust in FCA practices acted as an impediment. To these instructors, FCA practices are not taken seriously by student teachers. In other words, the assessment culture encourages student teachers to believe in summative assessment as the sole type of assessment that would impact their careers. So, it would seem impractical for an instructor in these contexts to use FCA for purposes other than training students to collect more grades in the final exam, i.e. teach to the test. This reveals the extent to which the power of summative assessment tends to control instructors' practice even if they believe otherwise. Furthermore, some contextual constraints were reported in the interview to be highly influential on current practices. For instance, the issue of regularity of FCA practice was investigated and it was shown that practice of formative assessments in the classroom tended to be average in Saudi Arabia and Libya and below average in Egypt (see table 5 below). The main reason behind this irregularity was large student teachers numbers. In this respect, one participant stated, "our section has too many students and not many teacher with much time. Marking assessment tasks every now and then is just not practical". The interviews also revealed the issue of the impact of formative assessment. To these participants, student teachers show explicit distrust in FCA due to the inherent belief that they either have a marginal impact or even no impact at all on their final status in terms of success. Hence, instructors' efforts in this respect might be taken somewhat seriously by student teachers only when university regulations indicate that FCA counts towards the final grades. On the other hand, instructors feel more restrictions imposed by the contextual constraints of student teachers numbers and the summative examination plethora inherent in the assessment culture. This seems to justify instructors' views with regard to the extent to which FCA practices fulfil the teaching objectives. In this respect, responses even support the views that practices are not fulfilling to objectives of the courses as assigned by instructors. 
TABLE 5.

OVERALL MATRIX OF INSTRUCTORS' EVALUATION OF FCA

\begin{tabular}{|c|c|c|c|c|c|c|c|}
\hline & Aspect & & Excellent & Above Average & Average & Below Average & Extremely Poor \\
\hline \multirow[t]{3}{*}{1.} & \multirow{3}{*}{$\begin{array}{l}\text { Reporting what knowledge and } \\
\text { skills of writing have been learnt }\end{array}$} & Egypt & & & & & \\
\hline & & Saudi & & & & & \\
\hline & & Libya & & & & & \\
\hline 2. & $\begin{array}{l}\text { Accurately reflecting student } \\
\text { learning }\end{array}$ & $\begin{array}{l}\text { Egypt } \\
\text { Saudi } \\
\text { Libya }\end{array}$ & & & & & \\
\hline \multirow[t]{3}{*}{3.} & \multirow{3}{*}{$\begin{array}{l}\text { Providing students with } \\
\text { information about their writing } \\
\text { performance }\end{array}$} & Egypt & & & & & \\
\hline & & Saudi & & & & & \\
\hline & & Libya & & & & & \\
\hline \multirow[t]{3}{*}{4.} & \multirow[t]{3}{*}{$\begin{array}{l}\text { Reporting long term progress in } \\
\text { writing }\end{array}$} & Egypt & & & & & \\
\hline & & Saudi & & & & & \\
\hline & & Libya & & & & & \\
\hline \multirow[t]{3}{*}{5.} & \multirow{3}{*}{$\begin{array}{l}\text { Providing students with } \\
\text { feedback about their writing }\end{array}$} & Egypt & & & & & \\
\hline & & Saudi & & & & & \\
\hline & & Libya & & & & & \\
\hline \multirow[t]{3}{*}{6.} & \multirow[t]{3}{*}{ Motivating students to write } & Egypt & & & & & \\
\hline & & Saudi & & & & & \\
\hline & & Libya & & & & & \\
\hline \multirow[t]{3}{*}{7.} & \multirow[t]{3}{*}{ Fulfilling to course objectives } & Egypt & & & & & \\
\hline & & Saudi & & & & & \\
\hline & & Libya & & & & & \\
\hline \multirow[t]{3}{*}{8.} & \multirow{3}{*}{$\begin{array}{l}\text { Fulfilling to students' learning } \\
\text { objectives }\end{array}$} & Egypt & & & & & \\
\hline & & Saudi & & & & & \\
\hline & & Libya & & & & & \\
\hline
\end{tabular}

Compared to their views of what FCA should be like, instructors' evaluations of FCA practices revealed huge discrepancies between theory and practice. This was made obvious through the interviews where the majority of participants indicated the need for change. A high percentage expressed a lack of institutional support in this respect. In other words, regulations within the universities involved in this study often prescribe issues that the contextual constraints would make them impractical and unrealistic. For them, the institutional role, especially in higher education, is much more important than the prescription of regulations and course specifications. It was also noticed that the sever lack of communication among colleagues about FCA and the way it has been de-emphasized not only by the Education system but by the assessment culture as well.

\section{DisCUSSIONS AND CONCLUSION}

This study attempted to provide a snapshot of the assessment culture in foreign language teacher education programs in Egypt, Saudi Arabia and Libya. The main feature of the study findings is the paradox between theory and practice. Participants referred to a well-perceived distrust in formative assessment among student teachers. The study drew attention to irregularity of formative assessment practices on the part of instructors who therefore deemed this form of assessment as invalid tool for monitoring teaching performance or students' learning. The study suggested that there is an inherent de-emphasis on the part of the education system and that leads students, instructors and the community to believe more in summative assessments as the only acknowledged assessment tool that would influence students' careers. According to the participants of the study, this of course reflects itself in the negative attitudes held towards 
formative assessment practices by many stakeholders. An implicit message in the interview, however, expressed a lack of institutional support in this respect. In other words, universities regulations often prescribe issues that the contextual constraints would make them idealistic.

It was also revealed that instructors implicitly criticized their institutions with regard to preaching unrealistic values. The institutions impose regulations that conform to theoretical advance in the field, but do not correspond to reality. Findings therefore suggest that although the potentialities of this type of assessment have been well established as it is believed to have a beneficial impact on levering students' learning to the extent that more and more educational bodies consider it worth exploring and exploiting, the assessment culture in Egypt, Saudi Arabia and Libya seemed to have established a paradox between theory and practice. To sum, FCA in the contexts involved is seen as a main concern for policy makers, school administrators, and instructors, but actual practice is different.

\section{REFERENCES}

[1] Anderson, R. S. (1998). Why talk about different ways to grade? The shift from traditional Assessment to alternative assessment, New Directions for Teaching and Learning, 74, 5-16.

[2] Ash, D., \& Levitt, K. (2003). Working within the Zone of Proximal Development: Formative assessment as professional development. Journal of Science Teacher Education, 14(1), 23-48

[3] Black, P., Harrison, C., Lee, C., Marshall, B. \& Wiliam, D. (2003). Assessment for Learning: Putting it into practice. England: Open University Press.

[4] Black, P. and Wiliam, D. (1998a). Assessment and classroom learning, Assessment in Education: Principles, Policy \& Practice, $5,(1), 7-47$.

[5] Black, P. and Wiliam, D. (1998b). Inside the black box: Raising standards through classroom assessment', Phi Delta Kappan, 80, (2), 139-149.

[6] Black, P. and Wiliam, D. (2003). In praise of educational research: formative assessment, British Educational Research Journal 29, (5), 623-637

[7] Bloom, B., Hastings, J. and Madaus, G. (1971). Handbook on the Formative and Summative Evaluation of Student Learning New York: McGraw-Hill.

[8] Boud, D. (1995). Assessment and learning: Contradictory or complementary?'. In Knight, P.(Ed), Assessment for Learning in Higher Education. (pp. 35-48). London: Kogan.

[9] Briggs, M., Martin, C., Woodfield, A. \& Swatton, P. (2003). Assessment for learning and teaching in primary schools (Achieving QTS). Exeter: Learning Matters Ltd.

[10] Carless, D., Joughin, G. \& Mok, M. (2006). Learning-oriented assessment: principles and practice, Assessment and Evaluation in Higher Education, 31(4), 395-398.

[11] Crooks, T. (1988). The Impact of Classroom Evaluation Practices on Students, Review of Educational Research, 58, (4), 438481.

[12] Dietel, R., Herman, J. and Knuth, R. (1991). What Does Research Say About Assessment?, North Central Regional Educational Laboratory. Available at: http://methodenpool.unikoeln.de/portfolio/What\%20Does\%20Research\%20Say\%20About\%20Assessment.htm . Access date: 20.04.2013.

[13] Fautley, M. and Savage, J. (2002). Assessment for learning and teaching in secondary schools (Achieving QTS). Exeter: Learning Matters Ltd.

[14] Gipps, C. (1999). Socio-cultural aspects of assessment, Review of Research in Education, 24, 355-392.

[15] Greer, L. (2001). Does changing the method of assessment of a module improve the performance of a student?, Assessment \& Evaluation in Higher Education, 26, (2), 127-138.

[16] Hargreaves, E. (1997). The Diploma Disease in Egypt: learning, teaching and the monster of the secondary leaving certificate, Assessment in Education: Principles, Policy \& Practice, 4, (1), 161-176.

[17] Hattie, J. and Timperley, H. (2007). The Power of Feedback, Review of Educational Research, 77, (1), 81-112.

[18] Irons, A. (2008). Enhancing Learning through Formative Assessment and Feedback. New York: Routledge.

[19] James, M. and Pedder, D. (2006). Beyond method: Assessment and learning practices and values, Curriculum Journal 17, (2), 109-38.

[20] Jones, C. (2005). Assessment for learning: Vocational learning support programme: 16-19. Published by the Learning and Skills Development Agency. Available at: www.LSDA.org.uk.

[21] Keppell, M., Au, E., Ada, C. \& Chan, C. (2006). Peer learning and learning-oriented assessment in technology-enhanced environments, Assessment \& Evaluation in Higher Education, 31, (4), 453-464.

[22] Knight, P. and Yorke, M. (2003). Assessment, learning and employability. Maidenhead, UK: Open University Press.

[23] Lodico, Marguerite; Spaulding, Dean \& Voegtle, Katherine. (2006). Methods in educational research: from theory to practice. John Wiley \& Sons, Inc.

[24] McMillan, J. (2001). Essential Assessment Concepts for Teachers and Administrators. California: Corwin Press, Inc.

[25] Natriello, G. (1987). The impact of evaluation processes on students, Educational Psychologist, 22, (2), 155-175

[26] Hargreaves, E. (1997). The Diploma Disease in Egypt: learning, teaching and the monster of the secondary leaving certificate, Assessment in Education: Principles, Policy \& Practice, 4, (1), 161-176

[27] Sadler, R. (1998). Formative assessment: Revisiting the territory, Assessment in Education: Principles, Policy \& Practice, 5, (1), 77-79

[28] Scriven, M. (1967). The methodology of evaluation. In Tyler, R. W, Gagne, R. M. and Scriven, M.(Eds) Perspectives of curriculum evaluation (pp. 39-83). Chicago: Rand McNally.

[29] Shepard, L. (2000). The role of assessment in a learning culture, Educational Researcher, 29, (7), 4-14. 
[30] Stiggins, R. J. and Bridgeford, N. J. (1985). The Ecology of Classroom Assessment, Journal of Educational Measurement, 22, (4), 271-286.

[31] Stiggins, R. J. (2002). Assessment crisis: The absence of assessment for learning, Phi Delta Kappa International, 83 (10) 758 765.

[32] Teasdale, A. and Leung, C. (2000). Teacher assessment and psychometric theory: a case of paradigm crossing?, Language Testing 17, (2), 163-184.

[33] Torrance, H. and Pryor, J. (1998). Investigating formative assessment: teaching, learning and assessment in the classroom. Philadelphia: Open University Press.

[34] Yorke, M. (2003). Formative assessment in higher education: Moves towards theory and the enhancement of pedagogic practice, Higher Education, 45, 477-501.

[35] Wildemuth, B. (1984). Alternatives to standardized tests, Princeton, NJ: ERIC Clearinghouse on Tests, Measurement, and Evaluation: Educational Testing Service. [Online]. Available at: http://www.eric.ed.gov (Accessed: 20/04/2013).

[36] Wiliam, D. and Black, P. (1996). Meanings and consequences: A basis for distinguishing formative and summative functions of assessment?, British Educational Research Journal, 22, (5), 537-548.

[37] Wiliam, D., Lee, C., Harrison, C. and Black, P. (2004). Teachers developing assessment for learning: impact on student achievement, Assessment in Education, 11, (1), 49-65.

[38] Wise, S. L., \& DeMars, C. E. (2005). Low examinee effort in low-stakes assessment: Problems and potential solutions. Educational Assessment, 10, 1-17.

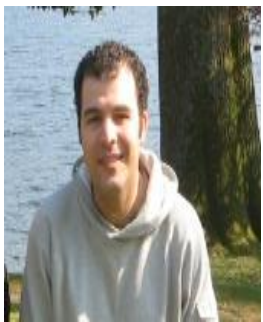

Khaled M. El ebyary obtained his PhD in Education and Applied Linguistics from Newcastle University in the UK. His major research interests are CALL, language assessment, bilingualism, teacher training and differentiation research. Dr El ebyary has a number of publications and he has done a number of international conference papers in the United States, Spain, France, Sweden, the UK and the Middle East. 